

\title{
A metodologia da Resolução de Problemas: uma proposta interdisciplinar sobre agrotóxicos na Educação de Jovens e Adultos
}

\begin{abstract}
Resumo
Este artigo apresenta a análise de uma experiência de utilização da metodologia de Resolução de Problemas (RP) no Ensino Médio na modalidade da Educação de Jovens e Adultos (EJA). O objetivo desta investigação é analisar as formas de contribuição da sequência didática implementada para o desenvolvimento de conhecimentos conceituais, procedimentais e atitudinais relacionados com os impactos ambientais que os agrotóxicos podem causar. Para a coleta de dados, foram utilizados o Diário de Campo dos pesquisadores, o questionário de avaliação da proposta e a gravação do áudio da aula em que os estudantes vivenciaram a RP. Os resultados apontam que a sequência didática implementada favoreceu as aprendizagens supracitadas quanto à RP e aos conhecimentos científicos trabalhados.
\end{abstract}

Palavras-chave: Educação Ambiental. Agrotóxicos. Educação de Jovens e Adultos. Resolução de Problemas.

\section{Daniel das Chagas de Azevedo Ribeiro}

Universidade Federal do Rio Grande do Sul - UFRGS - Porto Alegre/RS Brasil

professordanielufrgs@hotmail.com

Camila Greff Passos

Universidade Federal do Rio Grande do Sul - UFRGS - Porto Alegre/RS Brasil

camilagpassos@gmail.com

Tania Denise Miskinis Salgado Universidade Federal do Rio Grande do Sul - UFRGS - Porto Alegre/RS Brasil

tania.salgado@ufrgs.br

\footnotetext{
Para citar este artigo:

RIBEIRO, Daniel da Chagas de Azevedo; PASSOS, Camila Greff; SALGADO, Tania Denise Miskinis. A metodologia da Resolução de Problemas: uma proposta interdisciplinar sobre agrotóxicos na Educação de Jovens e Adultos. Revista Linhas. Florianópolis, v. 20, n. 43, p. 205-233, maio/ago. 2019.
} 


\title{
Problem-Solving Methodology: an interdisciplinary proposal about pesticides in Youth and Adults Education
}

\begin{abstract}
This article presents the analysis of an experience using the Problem Solving methodology (RP) in High School in the modality of Youth and Adults Education (EJA). The objective of this research is to analyze the forms of contribution of the didactic sequence implemented to the development of conceptual, procedural and attitudinal knowledge related to the environmental impacts that Pesticides can cause. For the data collection, we used the Field Diary of the researchers, the proposal evaluation questionnaire and the audio recording of the class in which the students experienced Problem Solving (RP). The results indicate that the didactic sequence implemented favored the aforementioned learning regarding Problem Solving (RP) and scientific knowledge worked.
\end{abstract}

Keywords: Environmental Education. Pesticides. Youth and Adults Education. Problem Solving. 


\section{Introdução}

Muito se fala, no Brasil, acerca da inclusão social por intermédio da educação, uma vez que os estudos são uma importante ferramenta que viabiliza o crescimento pessoal e profissional. Assim sendo, o conhecimento torna-se primordial, principalmente na sociedade moderna, na qual as mudanças no âmbito do trabalho, e a utilização de novas tecnologias, que se aperfeiçoam constantemente, exigem um profissional bastante qualificado para atuar em diferentes funções no mercado de trabalho. Nesse contexto, ressaltamos os alunos da EJA. A EJA é uma modalidade de ensino reconhecida pela LDB 9.394/96 que em seu art. 37 ressalta: "A Educação de Jovens e Adultos será destinada àqueles que não tiveram acesso ou continuidade de estudos no ensino fundamental e médio na idade própria” (BRASIL, 1996, p. 15). Dessa maneira, a EJA aparece como uma motivação aos jovens e adultos, propiciando que eles retornem à sala de aula. Além disso, um dos propósitos principais da EJA é disponibilizar aprendizagem e qualificação constantes, com o intuito de ensejar um extenso desenvolvimento com emancipação dos educandos, constituindo-se como modalidade que extrapola o ensino direcionado à transmissão de conteúdos, enfocando o desenvolvimento das capacidades cognitivas.

Tendo em vista as características específicas dos alunos da EJA, diferentes daqueles que tiveram a chance de estudar na "idade apropriada", percebemos que a seleção de conteúdos, materiais didáticos e metodologias de ensino e de avaliação devem ter um olhar diferenciado por parte dos docentes, uma vez que, em sua maioria, são cidadãos que trabalham durante o dia e em período integral. Desse modo, o docente deve trabalhar de maneira a motivar no aluno o gosto pelo aprender, numa proposta dinâmica que leve esse aluno a refletir, a interagir para se apropriar do conhecimento. Num processo assim, o professor desempenha um papel primordial, qual seja, o de agir como mediador do processo de construção do conhecimento, empregando um "método que seja ativo, dialógico, crítico e criticista" (FREIRE, 1979, p. 39), permitindo uma interação maior entre docente e discente e beneficiando o processo de ensinoaprendizagem.

Da mesma maneira, como se pode observar em diversas pesquisas acerca da responsabilidade que a educação escolar precisa ter em relação ao desenvolvimento dos educandos, Lipman (1995) enfatiza a incapacidade de se pressupor que os alunos têm 
condições de aprender a pensar melhor por intermédio de uma metodologia de ensino que pouco os motiva a refletir, observando, também, que muitos docentes não reestruturam seus planos de aula, pois, de acordo com tais professores, esse seria um esforço desnecessário quando se pretende aperfeiçoar as competências que os alunos já deveriam ter trazido para a sala de aula. Ademais, o estudioso identifica quatro grupos de habilidades que se fazem necessárias para os propósitos educacionais, recomendando que os educandos possam consolidá-las e desenvolvê-las por intermédio de atividades oportunizadas pelos educadores em suas aulas: habilidade de investigação, habilidade de raciocínio, habilidade de organização de informações, habilidade de tradução (LIPMAN, 1995).

Pesquisadores da Didática das Ciências defendem a utilização da estratégia de RP nas diferentes etapas e modalidades da Educação Básica, incluindo a EJA. Alguns estudiosos entendem que essa metodologia é capaz de contribuir para o processo de ensino e aprendizagem dos alunos (GOI; SANTOS, 2009; ECHEVERRÍA; POZO, 1998; POZO, 1998; LAUDAN, 1977). Nessa proposta didática, os estudantes são estimulados a explorar as ideias e propor tarefas que encorajam a discussão e o debate sobre como as coisas funcionam, desenvolvendo soluções para diferentes aspectos de um problema contextual, muitas vezes se diferenciando dos modelos tradicionais, uma vez que os problemas sugeridos abordam assuntos amplos, com questões abertas e sugestivas, possibilitando ao estudante a construção do seu conhecimento através de suas próprias habilidades (GOI; SANTOS, 2009).

Perguntamos, então, o que é uma situação-problema nesse contexto? De acordo com Echeverría e Pozo (1998):

Uma circunstância apenas pode ser concebida como um problema na medida em que exista um reconhecimento dela como tal, e na medida em que não disponhamos de procedimentos automáticos que nos permitam solucioná-los de forma mais ou menos imediata sem determinar, de alguma forma, um processo de reflexão ou uma tomada de decisões sobre a sequência de passos a serem seguidos. Além disso, um problema é, de certa forma, uma situação nova ou diferente do que já foi aprendido, que requer a utilização estratégica de técnicas já conhecidas. (ECHEVERRÍA; POZO, 1998, p. 16) 
De acordo com Laudan (1977), os problemas são o ponto central do pensamento científico e as teorias o seu resultado final. Laudan (1977) concebe a Ciência como uma atividade de RP, que gera um progresso cognitivo e que se relaciona às aspirações intelectuais da Ciência. O autor ressalta que as teorias são cognitivamente relevantes quando proporcionam resoluções adequadas aos problemas, por isso a função da teoria é resolver ambiguidades e encontrar resoluções adequadas para as situações problemáticas.

Nesse sentido, entendemos que com a utilização da perspectiva da aprendizagem por RP favorecemos o desenvolvimento das atitudes inerentes à atividade científica, como questionar-se, elaborar e resolver problemas e relacionar o conhecimento científico com os fenômenos vivenciados no dia a dia.

Pensando dessa maneira, é que realizamos um trabalho interdisciplinar entre as disciplinas de Química e Língua Portuguesa com uma turma da EJA, tendo como metodologia a RP, contextualizando nosso trabalho com a temática ambiental dos Agrotóxicos. Nesse sentido, o objetivo desta investigação é analisar as formas de contribuição da sequência didática implementada para o desenvolvimento de conhecimentos conceituais, procedimentais e atitudinais relacionados com os impactos ambientais que os agrotóxicos podem causar, conscientizando os alunos a respeito dessa problemática ambiental.

\section{Referencial teórico}

A Educação Ambiental (EA) é todo processo utilizado para preservar o patrimônio ambiental e criar modelos de desenvolvimento, com soluções limpas e sustentáveis, além da construção, por intermédio do indivíduo e da coletividade, de valores sociais, conhecimentos, habilidades, atitudes e competências voltadas para a conservação do meio ambiente, que é um bem de uso comum do povo, e primordial à sadia qualidade de vida e sua sustentabilidade (LOUREIRO; TORRES, 2014).

Assim sendo, a EA se apresenta como um conjunto de práticas educacionais com o intuito de estabelecer uma nova consciência ecológica em todas as disciplinas do currículo escolar. Por isso, as práticas de EA não devem somente transmitir 
conhecimentos acerca do meio ambiente, mas também promover a mudança de atitude, a determinação para a ação e a procura de soluções para o problema.

Além disso, somos amparados pela Lei $n^{\circ}$ 9.795/99, que diz que a EA deve estar presente na proposta pedagógica das escolas em todos os níveis de ensino (BRASIL, 1999a). Ademais, o artigo $10^{\circ}$ da lei, além de ressaltar o caráter processual e a prática integrada da educação ambiental, diz que deve ser trabalhada em todas as disciplinas de maneira interdisciplinar. Assim sendo, os professores podem utilizar métodos de ação coletiva para uma maior abrangência da temática ambiental.

Nesse contexto é que o trabalho por nós realizado apresenta a RP como forma de levar a cabo essa tarefa, com o intuito de formar educandos com a habilidade de tomar decisões fundamentadas e de participar de discussões na sociedade em que vivem no que diz respeito às questões ambientais.

Ainda sobre os conhecimentos da EA, os Parâmetros Curriculares Nacionais para o Ensino Médio (PCNEM) orientam que estes sejam contemplados nos componentes curriculares das três grandes áreas, visto que a complexidade das questões ambientais ultrapassa as barreiras das disciplinas. Nas orientações para a Química, a ênfase da temática de interesse deste trabalho (Agrotóxicos) é integrada à discussão sobre as propriedades da matéria e as interações do homem com a atmosfera (BRASIL, 1999b).

Os $\mathrm{PCN}+$ sugerem, quanto aos agrotóxicos, que o trabalho esteja associado à competência: representação e comunicação, como a leitura e interpretação de textos científicos, de jornais e de outros meios de comunicação sobre a utilização de agrotóxicos e outros tipos de poluentes (BRASIL, 2002a).

De forma convergente, as Orientações Curriculares para o Ensino Médio orientam o trabalho articulado dos conteúdos químicos aos aspectos sociocientíficos oriundos de questões ambientais, econômicas, sociais, políticas, culturais e éticas. Quanto ao estudo dos agrotóxicos, o documento sugere a discussão sobre a sua utilização e sua ação como poluente (BRASIL, 2006).

Nesse âmbito, na escola, o professor desempenha papel fundamental no processo de desenvolvimento de consciência sobre a importância da sustentabilidade ambiental e socioambiental, articulado ao estudo dos conteúdos escolares, necessitando de recursos 
didáticos e orientação contínua para desenvolver ações com esses propósitos. Assim, esse processo deve despertar nos indivíduos o cuidado individual e, principalmente, coletivo com a prática de atividades que possam causar impacto ambiental, tais como: a poluição do ar, dos rios, a degradação do solo, a pesca predatória, o desmatamento, a produção de energia com o uso de combustíveis poluentes, o destino do lixo, o consumo de alimentos com agrotóxicos etc. No que diz respeito ao meio ambiente e à nossa saúde, sabemos que os agrotóxicos têm sido utilizados há bastante tempo por agricultores no combate a pragas que afetam a produção de alimentos. Entretanto, seus efeitos não se restringem às pragas, podendo causar sérios danos ao ambiente e à saúde humana (MIRANDA et al., 2007).

Sendo tóxicos de uma forma geral, independentemente de qual composto seja utilizado na sua formulação, os agrotóxicos podem ser mais ou menos danosos à saúde humana e ao meio ambiente. Dessa maneira, a poluição do ambiente por esses produtos é uma das maiores preocupações ambientais e de Saúde Pública. Os efeitos da exposição aos agrotóxicos não atingem apenas os trabalhadores rurais, mas a população como um todo, pois esses produtos se dispersam pelo ar e são carregados através do solo representando um risco para a qualidade da água e do solo em regiões próximas a áreas agrícolas.

Mapa, 2014 apud Ribeiro, 2016 afirma que o uso dessas substâncias químicas é tão intenso que o Brasil, desde 2008, detém uma alarmante posição: a de maior consumidor de agrotóxicos do mundo (MAPA, 2014 apud RIBEIRO, 2016). Dados do Ministério da Agricultura, Pecuária e Abastecimento (MAPA) apontam o lançamento de 673,9 mil toneladas desses produtos no meio ambiente no ano de 2008. Esse número prosseguiu aumentando e, em 2011, supõe-se que tenha alcançado o patamar de 852,8 mil toneladas incluindo, nesse montante, produtos proibidos em outros países. Dessa maneira, percebemos o quanto nossa saúde pode estar sendo afetada de forma direta pelo consumo de alimentos com quantidades excessivas de agrotóxicos (MAPA, 2014 apud RIBEIRO, 2016). Entretanto, nossa revisão bibliográfica mostrou que a temática dos agrotóxicos associada à RP é pouco frequente na literatura, principalmente em pesquisas científicas na Educação Básica. Dessa forma, este estudo apresenta-se como um trabalho relevante no âmbito da educação em Ciências. 
Sobre a interdisciplinaridade na EJA, os documentos oficiais, LDB (BRASIL, 1996), PCNEM (BRASIL, 1999b), PCN+ (BRASIL, 2002a) afirmam que existe a necessidade de a área de Ciências da Natureza abordar de modo interdisciplinar e contextualizado o processo de ensino e aprendizagem visando à educação cidadã. Segundo os PCNEM (BRASIL, 1999b), a interdisciplinaridade é, assim, entendida como abordagem teóricometodológica com ênfase no trabalho de integração das diferentes áreas do conhecimento. Esses mesmos documentos defendem a interdisciplinaridade e a contextualização como princípios de organização do currículo.

Entendemos que levar em conta uma perspectiva interdisciplinar do saber, na organização do currículo de EJA, implica que o educando possa aprender muitas estratégias de interpretação, de leitura, de concepção do mundo, o que contribui para a sua formação como cidadão. Para Japiassu (1991), a interdisciplinaridade consiste em um trabalho em comum tendo em vista a interação das disciplinas científicas, de seus conceitos e diretrizes, de sua metodologia, de seus procedimentos, de seus dados e da organização de seu ensino. Além disso, trabalhar interdisciplinarmente é relacionar os conteúdos de duas ou mais disciplinas para aprofundar o conhecimento, promovendo um ensino mais ágil, dinâmico, participativo, colaborativo, momento em que uma disciplina interage com a outra. Assim sendo, a interdisciplinaridade implica conexões de ações disciplinares que visem a um benefício comum.

A interdisciplinaridade, de acordo com Saviani (2003), é imprescindível para a inauguração de um processo inteligente de construção do currículo de sala de aula informal, realístico e integrado. Por intermédio da interdisciplinaridade, o conhecimento passa de algo setorizado para um conhecimento integrado, no qual as disciplinas científicas interagem entre si.

Indo mais além, entendemos que as atividades centradas na interdisciplinaridade visam à formação de educandos que tenham uma visão ampla do mundo em que vivem e com o qual interagem, sendo capacitados a "articular, religar, contextualizar, situar-se num contexto e, se possível, globalizar, reunir os conhecimentos adquiridos" (MORIN, 2002, p. 29).

Percebemos, portanto, que o ensino e a aprendizagem envolvendo práticas interdisciplinares e contextualizadas são de grande valia na busca por uma educação que 
leve à formação de cidadãos participativos, criativos, capazes de transformarem o mundo em que vivem e a realidade na qual estão inseridos.

\section{Proposta metodológica de pesquisa}

Neste trabalho, optamos pela pesquisa qualitativa, pois esta perspectiva permite uma visão mais ampla de um cenário. Além disso, neste tipo de pesquisa o pesquisador participa do processo e descreve os significados nele presentes, possibilitando narrativas ricas e interpretações individuais. Ademais, as partes são mais importantes do que o todo, preocupa-se com a qualidade das informações (LÜDKE; ANDRÉ, 1986). Dentre as modalidades que a pesquisa qualitativa nos oferece, utilizamos o Estudo de Caso (YIN, 2001).

De acordo com Yin (2001), o Estudo de Caso é um método qualitativo que consiste, geralmente, em uma forma de aprofundar uma unidade individual. Ele serve para responder a questionamentos sobre os quais o pesquisador não tem muito controle em relação ao fenômeno estudado.

Lüdke e André (1986) argumentam que o Estudo de Caso se desenvolve em situação natural, é rico em dados descritivos, tem um plano aberto e flexível, focaliza a realidade de forma complexa e contextualizada. Os autores afirmam, ainda, que um caso é bem delimitado, podendo ser similar a outro caso, mas ao mesmo tempo pode ser bem distinto, uma vez que possui interesse próprio e singular. Dessa forma, cada um carrega sua especificidade e, consequentemente, suas características. O Estudo de Caso permite, ainda, a reflexão de uma realidade.

O Estudo de Caso descrito neste trabalho foi desenvolvido com 24 alunos, no turno noturno de uma escola pública estadual de Ensino Médio da cidade de Porto Alegre/RS, sendo os pesquisadores professores dos sujeitos deste trabalho. Todos os participantes assinaram termo de consentimento livre e esclarecido.

Os dados foram coletados através de registros no Diário de Campo (PORLÁN; MARTíN, 1998) dos pesquisadores, das produções escritas produzidas pelos educandos, da aplicação de questionário adaptado de estudos anteriores (GOI, 2004) e da gravação do áudio da aula, para posterior análise de conteúdos. Sobre esse assunto, Godoy (1995) 
afirma que na origem da análise de conteúdo, tem-se privilegiado as formas de comunicação oral e escrita. Argumenta que não se devem excluir outros meios de comunicação, pois qualquer comunicação que vincule um conjunto de significações de um emissor para um receptor pode, em princípio, ser traduzida pelas técnicas de análise de conteúdo. O método da análise de conteúdo aparece como uma ferramenta metodológica para a compreensão e interpretação da construção de significado daqueles que exteriorizam no discurso, parte do pressuposto que por trás do discurso aparente, esconde-se um outro sentido que convém descobrir (SILVA, et al., 2005).

\section{Proposta pedagógica}

Neste artigo, apresentamos a análise de uma experiência de utilização da RP em uma turma do terceiro ano do Ensino Médio, modalidade da EJA, contextualizando o tema agrotóxicos, sua definição, utilização e diferentes alternativas para essas substâncias químicas. A atividade na qual os estudantes vivenciaram a RP foi realizada na sala de vídeo da escola, em um único encontro de cinco períodos contínuos, para evitar a entrada e saída de alunos, de modo que todos participaram de todas as etapas do estudo.

Para tanto, seguimos uma sequência didática para implementar as atividades de RP com os estudantes. A sequência didática utilizada nesse processo formativo correspondeu aos seguintes seis momentos: I. Introdução dos alunos ao tema, através de um vídeo de motivação ("O Veneno está na mesa 1", disponível em https://www.youtube.com/watch?v=fnyZwl7022l) e da explanação feita pelos pesquisadores sobre os problemas ambientais que os agrotóxicos podem causar, propiciando a discussão com os estudantes sobre os conteúdos e contextos presentes nos problemas que seriam resolvidos; II. Organização das equipes de trabalho, em seis grupos de quatro pessoas, seguida da leitura e análise dos problemas, que seriam apresentados no decorrer do trabalho; III. Discussão dentro dos grupos para elaboração das hipóteses de trabalho e leitura dos materiais disponíveis para consulta, que incluíram o livro didático das Ciências da Natureza e Matemática da EJA (SCRIVANO, et al., 2013) e os três volumes do livro didático de Química (SANTOS; MÓL, 2013), adotados pela escola, pelo Programa Nacional do Livro Didático (PNLD). IV. Elaboração das apresentações com as resoluções; V. Plenária de apresentação das resoluções; VI. Debate coletivo, no qual os 
professores formadores realizaram um levantamento sobre as principais modelações de resolução e ressaltaram os conceitos fundamentais discutidos.

Os três problemas elaborados pelos pesquisadores são sobre a temática ambiental de agrotóxicos. De acordo com Pozo e Crespo (1998), os problemas propostos são classificados como escolares, os quais têm por objetivo desenvolver conceitos, procedimentos e atitudes cabíveis à Ciência que possibilitam a compreensão dos acontecimentos cotidianos; semiabertos, pois os enunciados apresentam parcialmente os subsídios necessários para a sua resolução; qualitativos, pois os estudantes podem utilizar conceitos científicos e teorias, sem a necessidade de cálculos ou raciocínio matemático; e teórico-práticos, porque aceitam estratégias experimentais e raciocínios teóricos para resolvê-los. Destacamos que os problemas semiabertos e qualitativos possibilitam que os próprios estudantes incorporem ideias e estratégias com as quais seja possível definir e resolver a tarefa.

Optamos por elaborar três problemas (mostrados no Quadro 1) com o objetivo de aprofundar o estudo dos conteúdos envolvidos no tema agrotóxicos.

Quadro 1 - Problemas formulados para trabalhar com a EJA

Problema 1: Combater pragas de lavouras, insetos ou animais transmissores de doenças sempre foi um grande desafio. Afinal, boa parte da produção se perde, vítima desses agentes. A Química entrou nessa batalha produzindo substâncias que amenizam esse problema, os chamados agrotóxicos. Você é professor de Química de uma zona rural de Porto Alegre e descobriu que alguns dos seus alunos são agricultores e não utilizam roupas de proteção apropriadas na aplicação de agrotóxicos nas lavouras. Você dará aula para esses estudantes e outros que também precisam saber sobre os cuidados que devem ter com os agrotóxicos. Faça uma pesquisa a respeito da definição de agrotóxicos e a finalidade para a qual são utilizados na agricultura. Dê exemplo de um agrotóxico, seu nome, estrutura química e os problemas de saúde e danos ao organismo humano que esse produto e outros podem causar. o que os agricultores podem fazer para amenizar os riscos à saúde no momento da aplicação de agrotóxicos?

Problema 2: Grande parte dos municípios brasileiros tem a agricultura como principal atividade econômica. Devido a doenças e ervas daninhas, os agricultores utilizam agrotóxicos para controlar essas pragas. Agrotóxicos são produtos utilizados na agricultura para controlar insetos, doenças, ou plantas daninhas que causam danos às plantações. Você foi contratado para analisar e resolver o problema da pulverização de agrotóxico em um arrozal. O agrotóxico é pulverizado por aviões em lavouras de arroz, mas nas imediações há 
moradores, animais e um rio corta a plantação. Quais seriam as consequências de realizar uma aplicação aérea de agrotóxicos sem um estudo prévio das condições meteorológicas e do entorno dessa pulverização? Pesquise sobre as alternativas para o cultivo de agriculturas sem a utilização de agrotóxicos ou, pelo menos, para redução de seu uso. Discuta, também, quais as vantagens e desvantagens de cada uma dessas alternativas e decida quais delas você considera mais eficiente para diminuir o uso de agrotóxicos.

Problema 3: O desenvolvimento tecnológico contribui de forma significativa para o aumento da produtividade agrícola, elevando a quantidade de alimentos produzida por área cultivada. Esse aumento de produtividade possibilitou uma maior disponibilidade de alimentos para a população. No entanto, a exploração agrícola tem sido a principal responsável pela destruição de áreas verdes, provocando desmatamentos, desertificação de grandes áreas, além do quê, o uso intensivo de produtos químicos na lavoura tem provocado sérios problemas ambientais. Diante disso, a agricultura orgânica tem aumentado muito no Brasil e tem tido um mercado promissor. O alimento orgânico é originário do reino vegetal e cultivado sob circunstâncias específicas sem uso de agrotóxicos, pesticidas, hormônios e outros. Pesquise a respeito da agricultura orgânica, seus princípios, suas práticas de cultivo, vantagens, desvantagens etc. Dê um exemplo de controle natural de pragas com aplicação de conhecimentos químicos e como alternativa para os agrotóxicos.

Fonte: os autores.

O Problema 1 inicia descrevendo como os agrotóxicos estão relacionados ao ensino de Química e pretendia, na sua resolução, que os alunos fossem capazes de perceber que essas substâncias químicas podem causar graves problemas à saúde humana. Além disso, outro objetivo era mostrar que o uso de roupas apropriadas (máscaras, botas, luvas etc.), na aplicação de agrotóxicos infelizmente ainda não é rotina para a maioria dos agricultores brasileiros. O Problema 2 estava relacionado com as metodologias de aplicação de agrotóxicos nas lavouras e com as alternativas para substituir essas substâncias químicas. Esperávamos que os alunos compreendessem que o estudo das condições meteorológicas é fundamental na agricultura. Uma das razões é o fato de a aplicação de agrotóxicos requerer voos de baixa altura, que têm grande risco de queda de avião em condições de chuva e vento fortes. Outra razão é que o agrotóxico, conforme o sentido do vento, pode atingir áreas vizinhas, contaminando o meio ambiente. Sobre as alternativas para substituir os agrotóxicos, pretendíamos que os alunos percebessem que existem inúmeras possibilidades e que todas as alternativas têm vantagens e desvantagens. O Problema 3 fala sobre os problemas ambientais que a 
exploração agrícola pode causar. Nesse contexto, quando solicitamos que os alunos pesquisem sobre a agricultura orgânica, é para que entendam que a produção com o uso de agrotóxicos pode comprometer a saúde e o ambiente, mesmo com o aumento da produtividade agrícola. Entretanto, a agricultura orgânica busca melhorar a qualidade dos alimentos sem contaminar produtores e consumidores, respeitando e preservando o ambiente. Além disso, o problema visava mostrar que diversas alternativas para o controle de insetos na lavoura têm sido desenvolvidas, como: uso de predadores naturais (controle biológico); esterilização por irradiação; rodízio de culturas; desenvolvimento de novas espécies por engenharia genética e controle químico com o uso de feromônios.

Após o término da sequência didática, para o fechamento das atividades, aplicamos um questionário com o objetivo de avaliarmos a contribuição da RP na compreensão dos conteúdos pelos alunos, bem como o desenvolvimento de habilidades de análise, de raciocínio, de organização de informações, de classificação, de investigação, de tomada de decisão, como apontamos no referencial teórico. Como o desenvolvimento da atividade aconteceu em um encontro contínuo, os vinte e quatro alunos responderam ao questionário.

\section{Resultados e discussão}

No início da atividade, o pesquisador Q (professor de Química), por intermédio de slides, explicou o assunto a ser tratado, qual seja: “Agrotóxicos, RP e Interdisciplinaridade". Antes, entretanto, questionou os estudantes a respeito do que são agrotóxicos. De acordo com os apontamentos do Diário de Campo, identificamos que muitos alunos prontificaram-se a responder. Um deles disse que os agrotóxicos são utilizados para combater bactérias; outro afirmou que servem para proteger as plantações das pragas; um terceiro assegurou que são utilizados para que as frutas fiquem mais bonitas. Por intermédio de perguntas condutoras, o pesquisador $\mathrm{Q}$ foi levando os alunos a perceberem os malefícios dos agrotóxicos e qual o seu verdadeiro uso. Dessa forma, o aluno que afirmou que o agrotóxico deixa a fruta mais bonita acrescentou a informação de que o agrotóxico faz mal para os consumidores dessa fruta. Assim sendo, o docente $Q$ asseverou que a fruta sem agrotóxico não é bonita, mas é mais saudável. Indagou o grupo, então, caso não houvesse agrotóxicos nos alimentos se 
viveríamos mais. Os alunos chegaram à conclusão de que teríamos uma vida mais saudável e, consequentemente, poderíamos ter uma vida mais longa.

Ainda por intermédio de perguntas condutoras, o pesquisador $\mathrm{Q}$ incitou os educandos a refletirem acerca da utilização dos agrotóxicos e suas implicações não só para a saúde humana, mas também para o meio ambiente. Assim procedendo, o docente Q fez com que os estudantes percebessem que os agrotóxicos contaminam também o solo, os lençóis freáticos e prejudicam a saúde dos consumidores.

Para Soares e Pinto (2001), os docentes precisam compreender "seu papel incentivador, mediador das ideias apresentadas pelos alunos, de modo que estas sejam produtivas, levando os estudantes a pensarem e a gerarem seus próprios conhecimentos" (p. 7), assim como já apontado no nosso referencial teórico por outros estudiosos (FREIRE, 1979; POZO, 1998).

Na continuação de suas explanações, o pesquisador Q afiançou que em 2008 o Brasil ultrapassou os EUA e assumiu o posto de maior mercado mundial de agrotóxicos, posição que mantém até hoje (MAPA, 2014 apud RIBEIRO, 2016). A partir dessa informação, assegurou que a contaminação dos alimentos se intensifica à medida que se utilizam quantidades cada vez maiores dessas substâncias. Desse modo, advêm graves consequências desse uso abusivo que trazem sintomas e doenças aos consumidores afetados. Sintomas de intoxicação aguda, tais como: fraqueza, tontura, vômito, perda de apetite, assim como sintomas de intoxicação crônica, quais sejam: lesões renais, doença de Parkinson, cânceres (PERES; MOREIRA, 2003), entre tantos outros apresentados nos slides. Prosseguiu sua explanação falando acerca dos riscos à saúde e contaminação de alimentos, assegurando que os agrotóxicos podem contaminar os seres humanos diretamente por diversas vias, quais sejam: via ocupacional, ambiental e alimentar, elucidando cada uma delas. À medida que explicava, trazia exemplos concretos ao grupo de uma pesquisa realizada em que se constatou que $29 \%$ dos alimentos analisados estavam contaminados por agrotóxicos (ANVISA, 2009 apud RIBEIRO, 2016). Alguns alunos deduziram que essa é uma porcentagem alta, então o professor Q perguntou se haveria uma possibilidade de cultivo de alimentos sem agrotóxicos. Sempre por intermédio de perguntas que levavam os educandos à reflexão, os alunos afirmaram que essa possibilidade existe. Partindo disso, explicou a utilização de uma agricultura 
sustentável, citando exemplos e esclarecendo-os, tais como a utilização de feromônios, policultura, corredores agrícolas e sistema de plantio direto (DAROLT, 2000; GHINI; BETTIOL, 2000; ZARBIN, et al., 2009).

Feito isso, deu início à explanação a respeito do que é a metodologia de RP. Esclareceu, de acordo com alguns referenciais teóricos utilizados nesta pesquisa, (ECHEVERRÍA; POZO, 1998; POZO, 1998; LAUDAN, 1977), o que são problemas e sua importância para o desenvolvimento de atitudes científicas nas aulas de Química.

Logo após, o professor $\mathrm{P}$, de Língua Portuguesa, explanou a respeito do que é interdisciplinaridade. O docente esclareceu que um planejamento interdisciplinar, tendo em vista as diversas disciplinas que possuem, acontece quando duas ou mais disciplinas interagem, relacionam seus conteúdos para aprofundar o conhecimento e levar dinâmica ao ensino. Entendemos que as afirmações feitas pelo professor $P$ sobre interdisciplinaridade estão de acordo com nossa revisão bibliográfica (JAPIASSU, 1991). Afirmou, também, que a relação entre os conteúdos disciplinares é o alicerce para um ensino mais atraente, no qual uma matéria ajuda a outra. Questionou, dessa maneira, no que a sua disciplina, Língua Portuguesa, poderia auxiliá-los para o trabalho que estavam prestes a realizar. Muitas contribuições vieram dos discentes. Um aluno disse que a Língua Portuguesa poderia ajudá-los a entender, a interpretar os problemas a serem resolvidos; outro afirmou que poderia auxiliá-los a escrever o relatório da resolução dos problemas; uma terceira aluna ponderou que, como já haviam discutido nas aulas de Português, deveriam adequar a linguagem oral da apresentação ao ambiente escolar, utilizando um português mais próximo da norma culta.

Após esse processo de contextualização dos princípios da proposta pedagógica, implementamos a sequência didática através dos seguintes seis momentos:

No momento I, de aproximação dos alunos ao conteúdo, a partir da visualização do vídeo sobre os problemas ambientais que os agrotóxicos podem causar, os estudantes mostraram-se bastante interessados e atentos às informações trazidas pelo filme. Terminada a apresentação, os educandos fizeram diversas perguntas aos pesquisadores, mostrando-se desconhecedores da maioria dos dados apresentados. Um dos docentes fez comentários sobre o vídeo e esclareceu dúvidas. Em seguida, perguntou a opinião da turma a respeito do filme. De acordo com registros do Diário de Campo, um aluno 
respondeu que achou bastante interessante, assim como todos os demais; outro aluno disse que havia muita política por trás desse assunto; outro assegurou que o governo incentiva o uso de agrotóxicos e quer dinheiro. Esse questionamento foi enriquecedor, pois possibilitou que os professores formadores falassem sobre o incentivo que 0 governo dá para agricultura produzida com agrotóxicos, o que não acontece com a agricultura orgânica, por exemplo. O assunto gerou uma discussão muito profícua com muitos alunos querendo opinar sobre a falta de incentivo às formas alternativas de plantio. Posteriormente, um dos pesquisadores acrescentou algumas informações relacionadas ao tema e, em seguida, solicitou que os educandos se reunissem em seis grupos de quatro componentes, contemplando o momento II da sequência didática. Organizados os grupos, o professor entregou aos alunos os problemas a serem resolvidos e solicitou que lessem com atenção a folha recebida, explicando-a. Eram três problemas, portanto, isso significa que houve sempre dois grupos com a mesma atividade. Nesse segundo momento, os sujeitos foram informados de que deveriam elaborar hipóteses de resolução para os problemas em sequência. Os grupos não apresentaram dificuldades quanto à compreensão dos enunciados e buscaram as informações nos materiais indicados pelos pesquisadores.

Durante o momento III, surgiram diálogos, arguições entre os estudantes e os professores formadores, em que os docentes questionavam-nos sobre suas hipóteses e afirmações. Novamente, percebemos a importância de o profissional da educação saber conduzir o educando a construir seu próprio conhecimento. De acordo com Carvalho e Gil-Pérez (2006), os professores assumem o papel de orientadores e mediadores nas atividades de investigação dirigida. Nesse sentido, podem argumentar sobre o problema em questão, estabelecendo relações para que os alunos possam compreendê-lo, auxiliar no acesso a outras fontes de conhecimento e discutir os dados obtidos interligando-os com as hipóteses levantadas, para verificar se a tarefa está efetivamente sendo realizada pelos caminhos utilizados. No decorrer do terceiro momento, os alunos leram com bastante atenção as atividades a eles destinadas. Surgiram dúvidas acerca do termo arrozal, e após a explicação do seu significado, houve o questionamento de como o arroz é plantado. Os pesquisadores explicaram as dúvidas e, através de afirmações e novas perguntas para os educandos, tentaram guiá-los para um melhor entendimento dos 
problemas e da temática em questão. Os materiais pesquisados para a RP foram os livros adotados pela escola do PNLD (SCRIVANO, et al., 2013; SANTOS; MÓL, 2013). Essas obras didáticas utilizadas no estudo trazem informações muito ricas sobre o uso dos agrotóxicos: definição, finalidade, consequências, características químicas e alternativas de substituição. Nesse sentido, entendemos que para essa proposta pedagógica, esses materiais foram suficientes para abordar a temática em questão convergindo com as orientações propostas para o Ensino Médio (BRASIL, 1999, BRASIL, 2002a, BRASIL, 2006).

No desenvolvimento do momento IV, na medida em que os alunos trabalhavam, os pesquisadores circulavam entre os grupos para auxiliá-los em possíveis dúvidas. Observou-se uma boa interação entre os alunos nos grupos, que se mostravam ativos e organizados, e talvez isso se tenha dado pelo fato de se tratarem de alunos adultos e/ou de uma temática que despertou o interesse de todos. Nessa etapa, foram elaboradas as resoluções dos problemas pelos grupos que, posteriormente, fizeram uma apresentação oral para toda a turma.

Terminado o tempo dado para a resolução dos problemas, começaram as apresentações, momento $V$. Os grupos 1 e 2, que trabalharam com o problema 1, não tiveram grandes dificuldades em resolvê-lo e propuseram resoluções próximas das esperadas. Entre outras informações apresentadas na plenária, o grupo 1 afirmou que o organismo humano pode ser muito prejudicado por diferentes tipos de agrotóxicos, que podem causar reações alérgicas, queda de resistência imunológica, lesões no fígado e nos rins, esterilidade masculina, entre outros. Já o grupo 2 citou como exemplo o $\mathrm{DDT}^{1}$, explicando que ele tem a capacidade de se acumular no tecido gorduroso dos animais e, em longo prazo, causar graves problemas de saúde como, por exemplo, alterações no sistema nervoso.

Coube aos grupos 3 e 4 solucionar o problema 2. Antes de começarem a apresentação, uma aluna do grupo 3 solicitou a palavra para dar um depoimento, dizendo que não sabia o quão grave era a utilização dos agrotóxicos de forma indiscriminada e o quão mal pode fazer à saúde das pessoas o consumo dessas substâncias. Os dois grupos explicaram que grandes quantidades de agrotóxicos são pulverizadas nas plantações e isso requer rigoroso estudo da velocidade do avião, do sentido do vento e da dosagem do

\footnotetext{
${ }^{1}$ Sigla de diclorodifeniltricloroetano.
} 
agrotóxico. Caso contrário, pode haver intoxicação do piloto, dos agricultores, contaminação do solo e das regiões vizinhas. Ambos os grupos conseguiram perceber que há possibilidades de substituição desses produtos, entretanto, tiveram dificuldade em perceber que cada uma das alternativas possui vantagens e desvantagens.

O Problema 3 foi solucionado pelos grupos 5 e 6. Relataram com clareza os princípios da agricultura orgânica, vantagens, desvantagens e discorreram sobre a preservação do meio ambiente. Não obstante, na apresentação do grupo 6, um aluno alegou que gostaria de ter conhecimentos mais aprofundados para resolver o problema, e afirmou que gostaria de inteirar-se mais sobre o tema. Alguns comentaram que se cada um evitasse comprar produtos com agrotóxicos, talvez a utilização desses produtos diminuísse. Outro aluno relatou que apenas com o trabalho proporcionado pelos pesquisadores é que ficou sabendo que o uso de agrotóxicos poderia afetar tanto assim o meio ambiente e a saúde das pessoas, atingindo inclusive fetos. Nenhum dos dois grupos conseguiu pesquisar sobre um exemplo de controle natural de pragas com aplicação de conhecimentos químicos e como alternativa para os agrotóxicos.

No momento $\mathrm{VI}$, os pesquisadores conduziram o debate sobre as principais modelações de resolução utilizadas, as dificuldades enfrentadas e os conceitos fundamentais abordados. Um dos pesquisadores perguntou à turma se o uso de agrotóxicos era algo bom ou ruim. Os alunos, em uníssono, responderam que era ruim. $\mathrm{O}$ pesquisador continuou a arrazoar sobre as consequências da sua utilização e, em seguida, fez um apanhado acerca da RP, da apresentação feita pelos educandos e ponderou sobre as dificuldades e o que os alunos não conseguiram resolver nos problemas. Logo após, indagou se havia algum comentário que a turma quisesse fazer. Pela análise de conteúdos feita para elaboração deste trabalho, verificamos muitos comentários a respeito da gravidade do uso de agrotóxicos nos alimentos e os danos causados à saúde humana e ao meio ambiente. Percebemos também um grande interesse dos educandos a respeito de como fazer para tirar ou diminuir a quantidade de agrotóxicos nos alimentos comprados. No momento dos questionamentos, os docentes explicaram, fornecendo algumas dicas como: retirar as folhas externas das verduras, pois geralmente concentram mais agrotóxicos; descascar as frutas, uma vez que muitos resíduos concentram-se nas cascas e lavar as frutas, verduras e legumes em solução de água (1 litro) e vinagre (4 colheres) 
por 20 minutos para retirar algumas substâncias indesejáveis.

As avaliações dos estudantes a respeito da proposta que foi apresentada foram colhidas através das perguntas 1, 2 e 3 do questionário aplicado após o término da sequência didática. Todos os 24 participantes da pesquisa responderam ao questionário.

$\mathrm{Na}$ questão 1, foram apresentadas aos alunos algumas afirmativas que dizem respeito a habilidades, conceitos e capacidades que pretendíamos desenvolver ou aprimorar com a RP. Na figura 1, mostramos o grau de concordância dos alunos com as afirmações apresentadas.

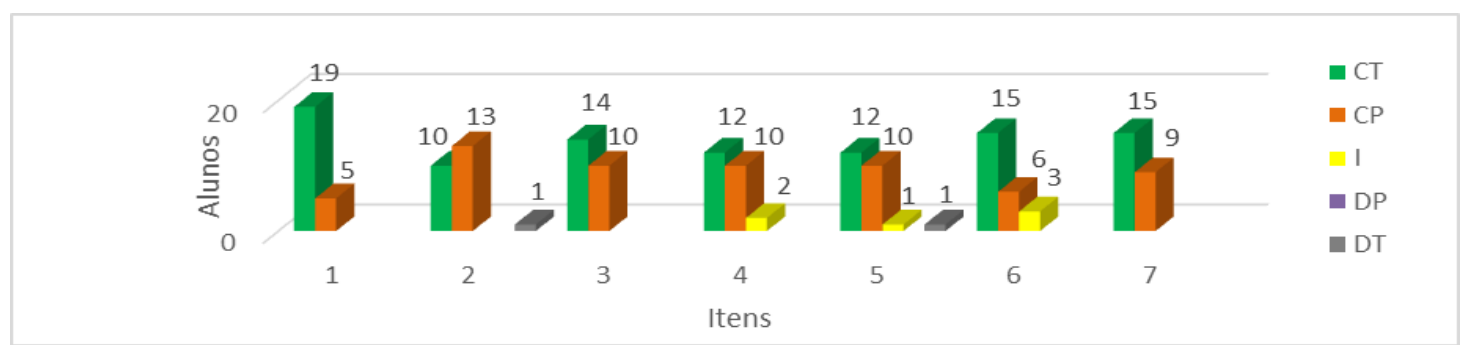

Figura 1: Grau de concordância dos alunos em relação às afirmações apresentadas nos itens que vão de 1 a 7 (1Desenvolvi minha habilidade de investigação na busca de soluções para resolver o caso; 2- Desenvolvi minha habilidade de organizar informações; 3- Desenvolvi minha habilidade de raciocínio; 4- Desenvolvi minha habilidade de análise; 5- Desenvolvi minha habilidade de classificação; 6- Desenvolvi minha capacidade de solucionar problemas e tomar decisões diante de problemas da vida real; 7- A RP contribuiu para a aprendizagem de conhecimentos de Ciências da Natureza e utilização da Língua Portuguesa). Legenda: $(C T=$ concordo totalmente; $C P=$ concordo parcialmente; $I$ = indeciso; $D P=$ discordo parcialmente; $D T$ = discordo totalmente).

A análise da Figura 1 permite afirmar que nos itens 1, 2, 3, 4 e 5, que dizem respeito ao desenvolvimento das habilidades de investigação, raciocínio, análise e classificação, respectivamente, a maioria dos alunos registrou respostas favoráveis à contribuição da RP para o seu aprimoramento. Tais habilidades são relevantes para se alcançar objetivos educacionais, como a educação científica para o exercício da cidadania (LIPMAN, 1995). Apesar de alguns itens apresentarem algumas respostas desfavoráveis à contribuição da metodologia, o resultado geral aponta para a efetividade da proposta de ensino no desenvolvimento das referidas habilidades, na opinião dos alunos. No item 6, 21 alunos concordaram com a contribuição da metodologia para o desenvolvimento da capacidade de solucionar problemas e tomar decisões diante de problemas da vida real; apenas três alunos ficaram indecisos nesse item. E no item 7, que diz respeito às impressões dos 
estudantes sobre a contribuição da metodologia para a aprendizagem de conhecimentos de Ciências da Natureza e a utilização da disciplina de Língua Portuguesa, todas as respostas foram favoráveis à sua aplicação. Acreditamos que os resultados refletem o envolvimento e a participação dos alunos durante a atividade proposta, e o trabalho que foi realizado em grupo contribuiu para a formação dos alunos.

Na pergunta de número 2, solicitamos que os educandos comentassem a respeito do trabalho interdisciplinar realizado com professores de Química e Língua Portuguesa, aplicando a RP. A maioria dos comentários demonstra uma boa concordância da turma referente à atividade:

“Foi bem melhor, a técnica de ensino da aula melhorou muito, deveriam aplicar mais vezes esse método"; "A aula foi um diferencial de outras disciplinas, tornou-se atraente"; "Foi interessante ter duas disciplinas dando aula do mesmo tema ao mesmo tempo”; “Na minha opinião, foi muito melhor de aprender”; “Inovador! Um fala, comenta e o outro reforça. É notável que o nosso método de aprendizagem é precário e coisas novas que têm como objetivo melhorar são sempre bem-vindas"; "Mais dinâmico e tive a percepção que realmente está tudo interligado"; "Gostei de trabalhar com este método de ensino".

Evidenciamos que as colocações dos alunos corroboram os pressupostos que fundamentam nossa investigação quanto à perspectiva interdisciplinar (JAPIASSU, 1991), pois elas apontaram a importância de existir um trabalho em conjunto entre os professores das diferentes disciplinas, mas com objetivos convergentes.

A pergunta 3 do questionário estava diretamente ligada à aceitação da RP pelos alunos. Todos responderam que gostaram de trabalhar com o método e apresentaram justificativas como: "Sim, pois foi uma metodologia de forma organizada e produtiva"; "Gostei, pois me ajudou a raciocinar e trabalhar em equipe"; "Gostei do método de pesquisa, mais divertido que as aulas tradicionais"; "Sim, gostei porque esclarecem muitas dúvidas e nos deu conhecimentos"; "Sim, ainda mais organizados em grupos, interagimos mais e desenvolvemos várias habilidades"; "Gostei, porque dessa forma aprendi muito mais sobre o tema"; "Sim, pois nos faz pensar em soluções para o mundo e questioná-las". 
A questão 4 do questionário estava relacionada com a autoavaliação quanto ao método proposto, a RP. Essa questão solicitava o grau de concordância dos alunos, usando a seguinte escala: 1 = DT Discordo totalmente; 2 = DP Discordo parcialmente; 3 = I Indeciso; 4 = CP Concordo parcialmente; $5=$ C Concordo. $O$ cálculo do valor de concordância foi determinado através do somatório do número de vezes em que a opção foi marcada, multiplicado pela pontuação atribuída a ela, e dividido pelo número total de respondentes. Analisando o Gráfico 1, observamos que a maioria dos alunos concorda que os problemas foram de fácil compreensão, com uma linguagem acessível, no entanto, foi necessária a realização de pesquisas para a resolução dos problemas e para chegarem a estratégias adequadas. A análise também demonstra que os estudantes não tiveram grandes dificuldades em compreender os problemas propostos sobre agrotóxicos.



Gráfico 1: Opiniões dos alunos sobre os problemas propostos.

Em relação às apresentações dos grupos e aos relatórios escritos, percebemos que a grande maioria dos alunos concorda que auxiliaram na Resolução do Problema e que os relatórios escritos ajudam a compreender o problema (Gráfico 2).

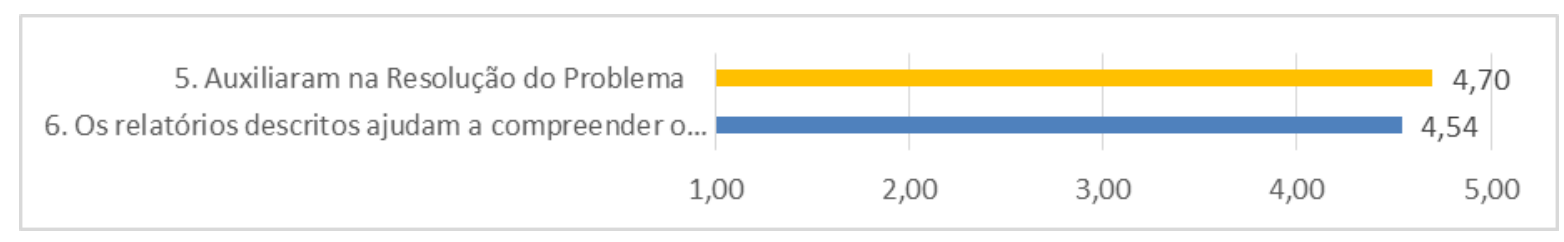

Gráfico 2: Opiniões dos alunos quanto às apresentações e relatório escrito.

Quanto às estratégias adotadas pelo grupo, conforme mostrado no Gráfico 3, os grupos concordam que foram eficazes para a resolução dos problemas e quanto maior o 
número de estratégias adotadas, maiores as chances de sucesso na obtenção das soluções. Além disso, os estudantes acreditam que essas estratégias favoreceram o trabalho em equipe.



Gráfico 3: Opiniões dos alunos quanto às estratégias adotadas pelo grupo.

O Gráfico 4 apresenta o grau de concordância dos alunos quanto ao trabalho através da RP. Conforme pode ser visualizado nesse gráfico, os alunos concordam que o trabalho contribuiu para a aprendizagem dos mesmos sobre a temática ambiental dos agrotóxicos. Consideram ainda que o tempo foi suficiente para a resolução dos problemas e que a metodologia utilizada nessa pesquisa contribuiu para a aprendizagem, podendo ser significativo para uma melhor compreensão dos alunos.

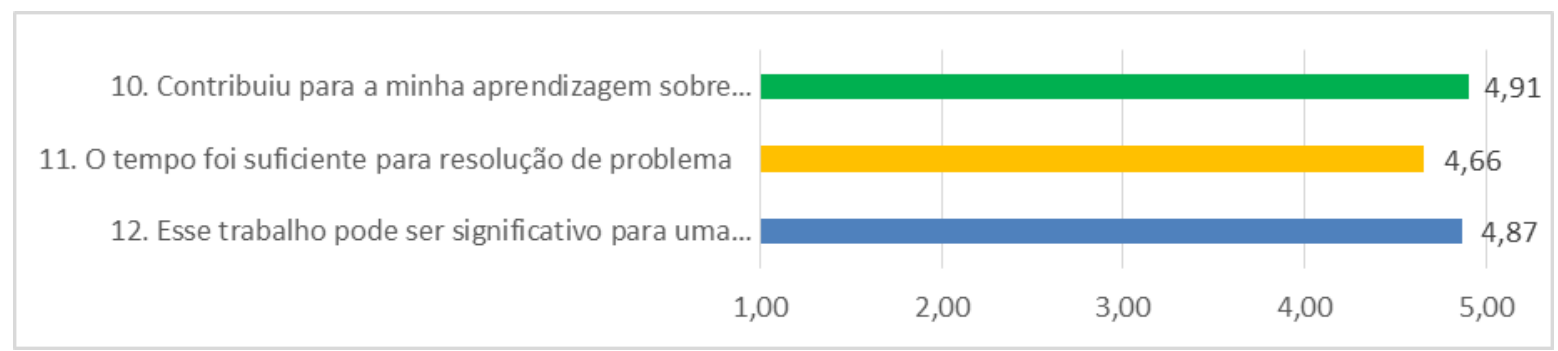

Gráfico 4: Opiniões dos alunos quanto ao trabalho através da RP.

Em relação à autoavaliação dos estudantes, o Gráfico 5 mostra que estes colaboraram com os demais colegas de grupo, ajudando de forma ativa na resolução do problema proposto, e se sentiram motivados para solucionar a atividade sugerida. Além disso, consideraram que aprenderam novos conhecimentos durante as etapas da RP. 


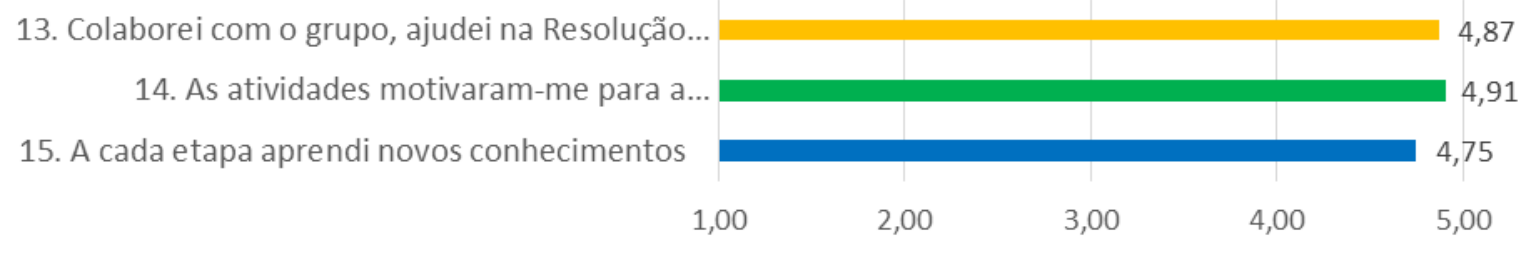

Gráfico 5: Opiniões dos alunos a respeito de sua conduta na aula sobre RP.

As análises dos gráficos permitem afirmar que nos itens apresentados, praticamente todos os alunos registraram respostas favoráveis à contribuição da RP para o seu aprimoramento sobre o tema em questão e perceberam uma nova possibilidade de metodologia para um melhor entendimento de outras aulas. Assim sendo, entendemos que os resultados mostram que o trabalho que foi realizado em grupo contribuiu para a formação dos alunos, pois favoreceu a socialização de hipóteses e conhecimentos.

Da mesma forma, acreditamos que a sequência dos problemas propostos favoreceu a discussão dos conteúdos de forma gradativa. Assim, compreendemos que a sequência didática implementada favoreceu aprendizagens conceituais relacionadas aos conhecimentos científicos trabalhados e, procedimentais, como a análise de referenciais bibliográficos, a confecção de relatórios e a defesa de ideias nas apresentações orais. Por conseguinte, entendemos que a metodologia aplicada neste trabalho possibilitou o estudo de uma temática relacionada às Ciências da Natureza de uma forma motivadora, dinâmica e reflexiva, de acordo, portanto, com os pressupostos da EJA.

Cabe ainda ressaltar que os livros didáticos, fontes de pesquisa para os alunos resolverem os problemas, afirmam que os Equipamentos de Proteção Individual (EPIs) amenizam os riscos de contaminação dos agricultores não se aprofundando em questões de intoxicação por agrotóxicos mesmo com a utilização de EPIs. Frente à sua extrema toxicidade, o uso de roupas de proteção não exclui os riscos para o aplicador, para a saúde humana e para o ambiente como um todo. Tomar cuidado é fundamental. Deve-se observar o horário de aplicação, o tempo, assim como a utilização de roupas que possam ser trocadas e lavadas; tomar banho com água corrente logo após a aplicação, não se alimentar durante a aplicação, observar os ventos, entre outros cuidados. De acordo com Veiga et al. (2007), em uma análise realizada a partir de dois casos: o primeiro em uma cultura de tomates em uma pequena comunidade rural brasileira, e o segundo em uma 
vinicultura na França, os EPIs usados nessas duas situações não protegeram, tampouco neutralizaram os perigos de contaminação por agrotóxico, conforme institui a legislação. Além disso, agravaram a contaminação dos trabalhadores rurais, uma vez que os EPIs acumulam diferentes tipos de produtos, havendo uma contaminação ainda maior. Segundo os autores, os procedimentos de limpeza expuseram os trabalhadores rurais a contaminações imediatas para aqueles que realizaram a limpeza, e mediatas, para os trabalhadores que mantiveram contato com o local onde a higienização foi realizada. Da mesma forma, os trabalhadores ainda se contaminaram ao vestirem e despirem EPIs contaminados.

Ademais, o substitutivo do Projeto de Lei de Flexibilização do uso de agrotóxico (PL 6299/02) prevê a mudança do nome agrotóxicos para defensivos fitossanitários (ANVISA, 2018). Acreditamos que a expressão em destaque traz em seu bojo a falsa sensação de segurança, o que poderia levar os consumidores a pensarem na disponibilidade de alimentos mais seguros para serem consumidos. Outrossim, o projeto retira da ANVISA a competência de realizar reavaliação toxicológica e ambiental desses produtos (ANVISA, 2018). A sugestão do substitutivo, que é de autoria do deputado Luiz Nishimori é de que não existam mais avaliação e classificação de produtos pelas áreas de saúde e meio ambiente, mas somente uma "homologação" de avaliação feita pelas empresas registrantes de produtos agrotóxicos (ANVISA, 2018). Além disso, o texto do substitutivo prenuncia a centralização de competências de registro, normatização e reavaliação de agrotóxicos no Ministério da Agricultura, afastando os órgãos federais da saúde e do meio ambiente dessas funções previstas na atual Lei dos Agrotóxicos (BRASIL, 2002b). No entanto, como já citado em nossa pesquisa, a sua utilização não acarreta danos apenas na agricultura, mas também afeta a saúde humana, os animais e o meio ambiente. Portanto, a competência de avaliação dos riscos ocasionados a essas áreas deve ser exercida pelos órgãos correspondentes. 


\section{Considerações finais}

Percebemos, tanto pelas observações dos pesquisadores como pela fala e respostas dos alunos, que a RP contribuiu para um melhor entendimento sobre a temática ambiental de agrotóxicos e também para sua formação como cidadãos. Constatamos um interesse muito grande por parte do grupo discente em relação ao que estava sendo apresentado. Esse interesse mostrou-se por intermédio da atenção dispensada pelos estudantes no momento em que os pesquisadores apresentavam as informações, assim como através dos diversos questionamentos realizados pelos educandos acerca da proposta pedagógica desenvolvida. O mesmo ocorreu durante a resolução dos problemas apresentados, pois os pesquisadores observaram todos os grupos trabalhando, tentando solucionar o problema, trocando ideias entre si, cada elemento do grupo dando a sua contribuição, relatando fatos de sua própria vivência. Notamos que os problemas os envolveram, pois faziam parte da sua realidade e, ao tentarem resolvê-los, estavam buscando uma solução para o bem comum de todos ali presentes e de sua comunidade.

Após a análise do questionário apresentado, observamos o quão produtivo foi o trabalho realizado, uma vez que a grande maioria dos implicados garantiu que a RP é uma metodologia diferenciada e que contribuiu para a aprendizagem sobre os agrotóxicos, sendo significativo para uma melhor compreensão do conteúdo que lhes foi apresentado.

Assim sendo, acreditamos que a RP seja adequada para que os estudantes aprendam a aprender, pois é uma metodologia centrada no aprendiz, incitando-o a participar ativamente na construção de seu próprio conhecimento. Com essa metodologia, pudemos analisar uma situação de sala de aula real, abarcando a RP, a qual foi conduzida unicamente por pesquisadores no ambiente ao qual pertencem os sujeitos deste estudo, uma escola pública de Porto Alegre, sem que este fosse modificado por agentes externos, uma vez que os próprios pesquisadores são professores dos sujeitos deste trabalho.

Observamos que os alunos adquiriram consciência sobre os problemas ambientais que os agrotóxicos podem causar no decorrer das etapas da pesquisa sobre RP, relacionando esse assunto com aspectos éticos, sociais, políticos, econômicos, que fazem 
parte da realidade em que estão inseridos. Ao mesmo tempo, foi possível construir conceitos das Ciências da Natureza associados aos da Língua Portuguesa e tornar o estudo sobre agrotóxicos relevante e motivador. Dessa forma, podemos dizer que a metodologia apresentou convergência com os propósitos da EJA (BRASIL, 1996).

\section{Referências}

ANVISA. Agência Nacional de Vigilância Sanitária. Agrotóxicos: Anvisa é contrária ao PL6299/02. Disponível em: <http://portal.anvisa.gov.br/noticias//asset_publisher/ FXrpx9qY7FbU/content/agrotoxicos-anvisa-e-contraria-ao-pl-6299-02/219201/ pop_up?_101_INSTANCE_FXrpx9qY7FbU_viewMode=print\&_101_INSTANCE_FXrpx9qY7F bU_languageld=pt_BR>. Acesso em: 15 ago. 2018.

\section{BRASIL. Congresso Nacional. Lei Federal n 9.394. Lei de Diretrizes e Bases da Educação} Nacional. Brasília, 20 de dezembro de 1996. Disponível em: <http://www.planalto.gov.br/ccivil_03/LEIS/L9394.htm>. Acesso em: 11 abr. 2019.

BRASIL. Lei n. 9795, de 27 de abril de 1999a. Dispõe sobre a educação ambiental. Institui a Política Nacional de Educação Ambiental e dá outras providências. Disponível em: <http://www.planalto.gov.br/ccivil_03/leis/l9795.htm>. Acesso em: 11 abr. 2019.

BRASIL. Ministério da Educação. Secretaria da Educação Média e Tecnológica.

Parâmetros curriculares nacionais: ensino médio. Brasília: MEC/SEMTEC, 1999b.

BRASIL. Ministério da Educação. Secretaria da Educação Média e Tecnológica. PCN+ ensino médio: orientações educacionais complementares aos parâmetros curriculares nacionais. Brasília: MEC/SEMTEC, 2002a. 
BRASIL. Casa Civil. Decreto $\mathrm{n}^{\circ} \mathbf{4 . 0 7 4}$, de 4 de janeiro de 2002b. Regulamenta a Lei $\mathrm{n}^{\mathrm{0}} 7.802$, de 11 de julho de 1989 , que dispõe sobre a pesquisa, a experimentação, a produção, a embalagem e rotulagem, o transporte, o armazenamento, a comercialização, a propaganda comercial, a utilização, a importação, a exportação, o destino final dos resíduos e embalagens, o registro, a classificação, o controle, a inspeção e a fiscalização de agrotóxicos, seus componentes e afins, e dá outras providências. Brasília, DF: Casa Civil, 2002. Disponível em: <http://www.planalto.gov.br/ccivil_03/decreto/2002/d4074.htm>. Acesso em: 15 ago. 2018.

BRASIL. Ministério da Educação. Secretaria da Educação Básica. Orientações curriculares para o ensino médio. Volume 2. Brasília: MEC/SEB, 2006.

CARVALHO, Anna Maria Pessoa; GIL-PÉREZ, Daniel. Formação de Professores de Ciências: tendências e inovações. São Paulo: Cortez, 2006. 120p.

DAROLT, Moacir Roberto. As Dimensões da Sustentabilidade: Um estudo da agricultura orgânica na região metropolitana de Curitiba-PR. 2000, 310f. Tese (Doutorado em Meio Ambiente e Desenvolvimento) - Universidade Federal do Paraná/Paris VII, Curitiba, 2000.

ECHEVERRÍA, María del Puy Pérez; POZO, Juan Ignacio. Aprender a resolver problemas e resolver problemas para aprender. In: POZO, J. I.; A solução de problemas. Porto Alegre: Artmed, 1998. p. 13-42.

FREIRE, Paulo. Educação e Mudança. 12 ed. São Paulo: Paz e Terra, 1979. 46p.

GHINI, Raquel; BETTIOL, Wagner. Proteção de plantas na agricultura sustentável. Cadernos de Ciência \& Tecnologia, v. 17, n. 1, p. 61-70, 2000.

GODOY, Arilda Schmidt. Pesquisa qualitativa: tipos fundamentais. Revista de Administração de Empresas, São Paulo, v. 35, n. 3, p. 20-29, 1995.

GOI, Mara Elisângela Jappe. A construção do conhecimento químico por estratégias de resolução de problemas. 2004. 151f. Dissertação (Mestrado em Ensino de Ciências e Matemática) - Universidade Luterana do Brasil, Canoas, 2004.

GOI, Mara Elisângela Jappe; SANTOS, Flávia Maria Teixeira. Reações de combustão e impacto ambiental por meio de resolução de problemas e atividades experimentais. Química Nova Na Escola, v. 31, p. 203-209, 2009.

JAPIASSU, Hilton. Prefácio. In: Fazenda, Ivani Catarina Arantes. Interdisciplinaridade: um projeto em parceria. 3. ed. São Paulo: Loyola, 1991. 119p.

LAUDAN, Larry. Progress and its problems. Towards a Theory of Scientific Growth. London: Routledge \& Kegan Paul. 1977. 257p.

LIPMAN, Matthew. O Pensar na Educação. Petrópolis: Vozes, 1995. 
LOUREIRO, Carlos Frederico; TORRES, Juliana Rezende. Educação Ambiental: dialogando com Paulo Freire. São Paulo: Cortez, 2014. 18op.

LÜDKE, Menga; ANDRÉ, Marli. Pesquisa em educação: abordagens qualitativas. São Paulo: EPU, 1986. 99p.

MIRANDA, Ary Carvalho de; MOREIRA, Josino Costa; CARVALHO, René de; PERES, Frederico. Neoliberalismo, uso de agrotóxicos e a crise da soberania alimentar no Brasil. Revista Ciência e Saúde Coletiva, Manguinhos, Associação Brasileira de Pós-Graduação em Saúde Coletiva, v. 12, n. 1, p. 7-14, jan./mar. 2007.

MORIN, Edgar. Educação e complexidade: os sete saberes e outros ensaios. São Paulo: Cortez, 2002.102p.

PERES, Frederico; MOREIRA, Josino Costa. É veneno ou é remédio? Agrotóxicos. In: Saúde e ambiente. Rio de Janeiro: Fiocruz, 2003. 384p.

PORLÁN Rafael; MARTíN, José. El diario del profesor: Un recurso para la investigación en el aula. 6 ed. Sevilla: Díada, 1998.

POZO, Juan Ignacio; CRESPO, Gómez. A solução de problemas em ciências da natureza. In: POZO, Juan Ignacio. A solução de problemas. Porto Alegre: Artmed, 1998. p. 67-102.

SANTOS, Wildson Luiz Pereira; MÓL Gerson de Souza. (Org.). Projeto de Ensino de Química e Sociedade: química cidadã. 2 ed. São Paulo: AJS. 2013.

RIBEIRO, Daniel das Chagas de Azevedo. Problemas ambientais causados por agrotóxicos: uma proposta de formação de professores de química viabilizando a metodologia da resolução de problemas. 2016. 134 f. Dissertação (Mestrado em Química) - Universidade Federal do Rio Grande do Sul, Porto Alegre, 2016.

SAVIANI, Nereide. Saber escolar, currículo e didática: problemas da unidade conteúdo/método no processo pedagógico. 4. ed. Campinas, SP: Autores Associados, 2003.

SCRIVANO, Carla Newton. et al. Ciências, transformação e cotidiano: ciências da natureza e matemática ensino médio: educação de jovens e adultos. 1. ed. São Paulo: Global. 2013. 510p.

SILVA, Cristiana Rocha.; GOBBI, Beatriz Chirto; SIMÃO, Ana Adalgisa. O uso da análise do conteúdo como uma ferramenta para a pesquisa qualitativa: descrição e aplicação do método. Organ. rurais agroindustriais, Lavras, v. 7, n. 1, p. 70-81, 2005.

SOARES, Maria Teresa Carneiro; PINTO, Neusa Bertoni. Metodologia da resolução de problemas. In: REUNIÃO ANPED, 24, 2001. Anais eletrônicos [...] Caxambu, 2001. p. 1-9. 
VIEGA, Marcelo Motta. et al. A contaminação por agrotóxicos e os equipamentos de proteção individual (EPIs). Rev. Bras. Saúde ocup., v. 32, n. 116, p. 57-68, dez. 2007.

YIN, Robert K. Estudo de caso: planejamento e métodos. 2. ed. Porto Alegre. Editora: Bookmam. 2001. 200p.

ZARBIN, Paulo; RODRIGUES, Mauro; LIMA, Eraldo. Feromônios de insetos: tecnologia e desafios para uma agricultura competitiva no Brasil. Química Nova, v. 32, n. 3, p. 722-731, abr., 2009.

Recebido em: 21/05/2018 Revisões requeridas em: 17/07/2018 Aprovado em: 30/08/2018

Universidade do Estado de Santa Catarina - UDESC Programa de Pós-Graduação em Educação - PPGE Revista Linhas Volume 20 - Número 43 - Ano 2019 revistalinhas@gmail.com 